\title{
Many roads to motor deficits: loss of dopamine signaling in direct or indirect basal ganglia pathway leads to akinesia through distinct physiological mechanisms
}

\author{
Gwendolyn G. Calhoon and Patricio O'Donnell* \\ Department of Anatomy and Neurobiology, University of Maryland School of Medicine, Baltimore, MD, USA \\ *Correspondence: podon002@umaryland.edu
}

\section{A commentary on}

Dissociable effects of dopamine on neuronal firing rate and synchrony in the dorsal striatum

by John M. Burkhardt, Xin Jim, and Rui M. Costa (2009) Front. Integr. Neurosci. 3:28.

Smooth execution of voluntary movement depends upon activity within the basal ganglia and its modulation by dopamine (DA) (Zhou and Palmiter, 1995; Groenewegen, 2003). In Parkinson's disease (PD), diminishing motor control is caused by the loss of DA projections from the substantia nigra pars compacta to the striatum (Poirier et al., 1975; Hornykiewicz, 1993), resulting in a reduction of extracellular striatal DA. D1-like and D2-like receptors have disparate patterns of expression and distinct physiological properties (Gerfen et al., 1990; Surmeier and Kitai, 1994; Taverna et al., 2008), and are expressed in separate neuronal populations involved in the basal ganglia direct pathway (D1) and indirect pathway (D2) (Albin et al., 1989; Alexander and Crutcher, 1990). Depletion of DA leads to changes in neuronal firing rate and synchrony among cells in the dorsal striatum (Costa et al., 2006), but the role of direct and indirect pathways on these changes is yet unclear.

In their recent contribution to Frontiers in Neuroscience, Burkhardt et al. (2010) investigate the individual contribution of each of these two receptor groups to altered firing rate and synchrony in the dorsal striatum following a paucity of DA signaling. Their findings indicate that blockade of either D1 or D2 receptors produces akinesia, but that the mechanisms underlying such loss of motor output are dissociable. The authors parse the roles of the D1 and D2 receptors in changing neuronal activity by systemically blocking the action of DA at both or either population of receptors using the specific D1 and D2 antagonists, SCH-23390 and raclopride, respectively. Electrode microarrays chronically implanted in the dorsal striata of freely moving mice monitored changes in single unit and local field potential (LFP) activity following administration of the antagonists. The authors discriminated between the primary output neurons of the dorsal striatum, the medium spiny neurons (MSNs), and the fast-spiking interneurons and large aspiny neurons based upon the half-width, firing frequency, and amplitude of the recorded waveforms. Single unit firing rate, relative power of different frequency oscillations in the LFP, and entrainment of firing to the LFP (measured as spike-triggered average) were considered following drug administration. As LFPs reflect electrical activity in a network of neurons and afferents (Bullock, 1997; Goto and O'Donnell, 2001), this final measurement provides an indication of the synchrony of individual units with neural ensembles within the dorsal striatum (Goldberg et al., 2004; Kuhn et al., 2005; Costa et al., 2006).

The effects of simultaneous blockade of the D1 and D2 receptors are consistent with the effects of DA depletion (Costa et al., 2006). Mice treated with both drugs are acutely akinetic. Single unit recordings of MSNs from these animals show changes in firing rate (most often a decrease in firing), and LFP recordings contain a general reduction in gamma band power following global DA antagonism. What is more, combined administration of SCH-23390 and raclopride causes the alignment of cell spiking with epochs of depolarization in a neural ensemble, as revealed by the trough of the LFP using spike-triggered averages. Interestingly, treatment with either antagonist alone produces akinesia similar in scope to that caused by both antagonists together; however, each antagonist results in distinct physiological outcomes. D2 receptor blockade caused a decrease in firing rate in most putative MSNs, as well as a change in the relative power of LFP oscillations, but insomuch as D2 blockade alone did not alter the entrainment of MSNs to the LFP, synchrony was found to be unrelated to the activity of DA at D2 receptors. By contrast, specific antagonism of D1 receptors resulted in MSN entrainment to the trough of the LFP, but had less impact upon firing rate and power in the LFP.

These observations suggest that changes in firing rate and LFP power following DA depletion arise from reduced signaling at D2 receptors, and that increased neuronal synchrony in the absence of DA arise from reduced signaling at D1 receptors. In fact, the probability that an individual neuron would become entrained to the LFP following administration of one or both antagonists was unrelated to whether it underwent a change in firing rate upon treatment. That these events are dissociated supports the conclusion that reduced DA signaling affects activity in the dorsal striatum independently via separate D1- and D2-mediated pathways. Thus, interfering with the D1-dependent direct pathway or the D2-dependent indirect pathway separately affects motor control by affecting striatal ensemble activity via different mechanisms involved in control of cell firing and neural assemblies. Furthermore, as D2 receptors have higher affinity for DA than D1 receptors (Richfield et al., 1989), it is possible that hypokinesia due to reduced direct pathway signaling may emerge earlier than that due to reduced indirect pathway signaling in PD. In this regard, Burkhardt and colleagues provide a hint at aspects of striatal physiology that could potentially inform more effective treatment strategies for PD. 


\section{REFERENCES}

Albin, R., Young, A. B., and Penney, J. B. (1989). The functional anatomy of basal ganglia disorders. Trends Neurosci. 12, 366-375.

Alexander, G. E., and Crutcher, M. D. (1990). Functional architecture of basal ganglia circuits: neural substrates of parallel processing. Trends Neurosci. 13, 266-271.

Bullock, T. H. (1997). Signals and signs in the nervous system: the dynamic anatomy of electrical activity is probably information-rich. Proc. Natl. Acad. Sci. U.S.A. 94, 1-6.

Burkhardt, J. M., Jin, X., and Costa, R. M. (2010). Dissociable effects of dopamine on neuronal firing rate and synchrony in the dorsal striatum. Front. Int. Neurosci. 3:28. doi: 10.3389/ neuro.07.028.2009.

Costa, R.M., Lin, S. C., Sotnikova, T., Cyr, M., Gainetdinov, R., Caron, M., and Nicolelis, M. A. L. (2006). Rapid alterations in corticostriatal ensemble coordination during acute dopamine-dependent motor dysfunction. Neuron 52, 359-369.

Gerfen, C. R., Engber, T.M., Mahan,L.C., Susel,Z., Chase, T. N., Monsma, F. J. Jr, and Sibley, D. R. (1990). D1 and $\mathrm{D} 2$ dopamine receptor-regulated gene expression of striatonigral and striatopallidal neurons. Science 250, 1429-1432.

Goldberg, J. A., Rokni, U., Boraud, T., Vaadi, E., and Bergman, H. (2004). Spike synchronization in the cortex-basal ganglia networks of Parkinsonian primates reflects global dynamics of the local field potentials. J. Neurosci. 24, 6003-6010.

Goto, Y., and O'Donnell, P. (2001). Network synchrony in the nucleus accumbens in vivo. J. Neurosci. 21 , 4498-4504.

Groenewegen, H. (2003). The basal ganglia and motor control. Neural Plast. 10, 107-120.

Hornykiewicz, O. (1993). Parkinson's disease and the adaptive capacity of the dopamine nigrostriatal system. Adv. Neurol. 60, 140-147.

Kuhn,A.A., Trottenberg, T., Kivi, A., Kupsch,A., Schneider, G. H., and Brown, P. (2005). The relationship between local field potential and neuronal discharge in the subthalamic nucleus of patients with Parkinson's disease. Exp. Neurol. 194, 212-220.

Poirier, L. J., Filion, M., Larochelle, L., and Pechadre, J. C. (1975).Physiopathology of experimental Parkinsonism in the monkey. Can. J. Neurol. Sci. 2, 255-263.

Richfield, E. K., Penney, J. B., and Young, A. B. (1989). Anatomical and affinity state comparisons between dopamine $\mathrm{D} 1$ and $\mathrm{D} 2$ receptors in the rat central nervous system. Neuroscience 30, 767-777.

Surmeier, D. J., and Kitai, S. T. (1994). Dopaminergic regulation of striatal efferent pathways. Curr. Opin. Neurobiol. 4, 915-919.

Taverna, S., Iligic, E., and Surmeier, D. J. (2008). Recurrent collateral connections of striatal medium spiny neurons are disrupted in models of Parkinson's disease. J. Neurosci. 28, 5504-5512.

Zhou, Q. Y., and Palmiter, R. D. (1995). Dopaminedeficient mice are severely hypoactive, adipsic, and aphagic. Cell 83, 1197-1209.

Received: 11 August 2010;accepted: 27 August 2010 published online: 08 December 2010.

Citation: Calhoon GG and O'Donnell P (2010) Many roads to motor deficits: loss of dopamine signaling in direct or indirect basal ganglia pathway leads to akinesia through distinct physiological mechanisms. Front. Neurosci. 4:168 doi:10.3389/fnins.2010.00168

Copyright $\odot 2010$ Calhoon and O'Donnell. Thisisanopen-access article subject to an exclusive license agreement between the authors and the Frontiers Research Foundation, which permits unrestricted use, distribution, and reproduction in any medium, provided the original authors and source are credited. 